\title{
Ovo em Pó na Alimentação de Leitões Recém-Desmamados 1
}

\section{Adriana Nogueira Figueiredo², Valdomiro Shigueru Miyada ${ }^{3}$, Carlos Eduardo Utiyama $^{4}$, Flavio Alves Longo ${ }^{4}$}

\begin{abstract}
RESUMO - Foram realizados dois experimentos para determinar a composição química, os coeficientes de digestibilidade de nutrientes e os valores de energia e proteína digestíveis do ovo em pó (OP) e avaliar o desempenho e os componentes sangüíneos e plasmáticos de leitões alimentados com dietas contendo OP. No Experimento I, foram utilizados oito leitões em um ensaio de digestibilidade. Os animais foram distribuídos em dois tratamentos e quatro repetições, sendo uma ração referência e uma teste (70\% da ração referência $+30 \%$ de OP). Utilizou-se a metodologia da coleta parcial de fezes $\left(0,5 \%\right.$ de $\left.\mathrm{Cr}_{2} \mathrm{O}_{3}\right)$. Os coeficientes de digestibilidade aparente do OP foram de 80,$81 ; 87,14 ; 82,00$ e 70,55\%, respectivamente, para a matéria seca, energia bruta, proteína bruta e extrato etéreo. A partir dos coeficientes de digestibilidade determinados e os valores de proteína bruta $(56,53 \%)$ e energia bruta $(5.897 \mathrm{kcal} / \mathrm{kg})$, foram calculados os valores de 43,90\% de proteína digestível e $5.140 \mathrm{kcal} / \mathrm{kg}$ de energia digestível para o OP. No Experimento II, foram utilizados 90 animais desmamados com 24 dias e 5,6 kg. Os tratamentos consistiram de cinco rações isonutritivas com níveis crescentes $(0,25,50$, 75 e 100\%) de substituição protéica do plasma sangüíneo (PS) da dieta pelo OP. O delineamento experimental foi o de blocos casualizados, com nove repetições por tratamento. Não houve diferença entre os tratamentos para as variáveis de desempenho na fase de 1-14 dias pós-desmame. Para a fase de 15-28 dias e para o período total, foi observada redução linear do GDP e CDR, com o aumento do nível de inclusão da proteína do OP. Para as variáveis dos componentes plasmáticos e sangüíneos não foram observadas diferenças significativas entre os tratamentos. Em função dos resultados obtidos, não foi viável a substituição do plasma sangüíneo pelo ovo em pó nas dietas de leitões durante a fase de creche.
\end{abstract}

Palavras-chave: desempenho, digestibilidade, ovo em pó, plasma sangüíneo, suíno

\section{Spray-Dried Egg for Wealing Pigs}

\begin{abstract}
Two experiments were carried out to determine the chemical composition, nutrients digestibility and digestible energy and protein of spray-dried egg (OP) and to study the performance and plasma and blood components of weanling pigs fed diets containing OP. In the Experiment I, eight pigs were used for digestibility assay. The animals were assigned to two treatments and four replications/treatment. The treatments consisted of a basal diet and test diet ( $70 \%$ of basal diet $+30 \%$ of OP). The method was the partial faeces collection $\left(0.5 \% \mathrm{Cr}_{2} \mathrm{O}_{3}\right)$. The apparent digestibility coefficients of dry matter, gross energy, crude protein and crude fat were, respectively, $80.81,87.14,82.00$, and $70.55 \%$. From the results of apparent digestibility coeficients and the values of crude protein $(56.53 \%)$ and gross energy $(5,897 \mathrm{kcal} / \mathrm{kg})$, values of $43.90 \%$ of digestible protein and $5,140 \mathrm{kcal} / \mathrm{kg}$ of digestible energy for OP were calculated. In the Experiment II, ninety pigs were weaned at 24 days of age with $5.6 \mathrm{~kg}$ live weight. The treatments consisted of five dietary levels of 0,25,50,75 and 100\%, as a replacement of plasma (PS) protein for OP protein. Pigs were alloted to a randomized block design with nine replications per treatment. No treatment effects were observed on performance for 1-14 day post-weaning phase. For the 15-28 d phase and for the total period, linear reductions of GDP and CDR were observed, as the dietary OP levels increased. No treatment effects were observed on plasma and blood components by the inclusion of spray-dried egg. It was not recommended to replace the PS by OP in nursery diets.
\end{abstract}

Key Words: digestibility, performance, spray-dried egg, spray-dried plasma, swine

\section{Introdução}

O desmame é um período crítico dentro do ciclo produtivo dos suínos, porque o leitão desmamado apresenta os sistemas imunológico e digestório ima- turos em um período de transição do alimento leite para uma ração seca, os quais, aliados ao estresse causado na desmama, prejudicam o desempenho do animal. Assim, o período logo após o desmame dos leitões tem trazido inúmeros problemas relacionados

\footnotetext{
1 Projeto financiado pela FAPESP, parte da dissertação de mestrado do primeiro autor.

2 Mestre em Ciência Animal e Pastagem, Departamento de Zootecnia, ESALQ/USP. Av. Pádua Dias 11, CEP: 13418-900, Piracicaba/SP.

E.mail: anogueiraf@yahoo.com.br

3 Docente do Departamento de Zootecnia, ESALQ/USP. E.mail: vmiyada@carpa.ciagri.usp.br

4 Alunos de doutorado em Ciência Animal e Pastagem, ESALQ/USP.
} 
com o tipo e qualidade das matérias-primas empregadas em sua nutrição, o que poderá influenciar o desempenho do animal não só nessa fase, mas também nas fases seguintes.

Entre os alimentos presentes nas dietas para leitões recém-desmamados, a maior atenção concerne à fonte protéica utilizada, uma vez que o consumo, ganho de peso, digestibilidade de nutrientes e a atividade das enzimas pancreáticas podem ser afetados pela sua qualidade (Makkink et al., 1994; Peiniau et al., 1996).

É sabido que uma alternativa para amenizar o desafio nutricional imposto pelo desmame é o uso de dietas complexas contendo leite em pó e também o plasma sangüíneo como fontes de proteína de qualidade. Entretanto, esses ingredientes por muitas vezes oneram o custo das rações.

Dessa forma, o ovo aparece como uma opção a ser estudada, pois é considerado uma fonte de proteína animal de excelente qualidade, de alto valor biológico e distribuição balanceada de vitaminas e minerais (Egg Products, 2000). Além disso, a facilidade com que os ovos são trincados e quebrados produz uma quantidade substancial de subprodutos que são inúteis para o consumo humano. De acordo com Harmon et al. (2001), aproximadamente $2 \%$ de todos os ovos de galinhas poedeiras produzidos são rejeitados.

A desidratação dos ovos que são descartados para o consumo humano é uma alternativa para viabilizar a utilização desse ingrediente na formulação de rações para suínos. Com a introdução do processamento de alimentos de origem animal pelo método do spray-dry, foi possível a obtenção de produtos de qualidade, mantendo íntegras suas características originais (Aguirre, 1979).

Os dados encontrados na literatura sobre a utilização do ovo em pó na alimentação de leitões ainda são bem inconsistentes. Nessmith et al. (1996) observaram que as dietas com ovo em pó resultaram no decréscimo do desempenho de leitões recém-desmamados, quando comparada com as dietas contendo ou farelo de soja ou soja extrusada ou farinha de peixe selecionada. Em trabalho conduzido por Norin et al. (1998) sobre a alimentação de leitões no desmame precoce segregado, nas dietas que continham ovo em pó, em níveis de 6 e $12 \%$ os leitões apresentaram menor ganho de peso comparados com os leitões que receberam a dieta padrão, baseada em farelo de soja, plasma desidratado e soro de leite.

Mais recentemente, Harmon et al. (2000) estuda- ram a substituição gradativa do plasma desidratado pelo ovo em pó em leitões desmamados entre 14 e 16 dias e concluíram que o ovo pode ser uma alternativa na substituição do plasma, uma vez que os resultados de conversão alimentar não apresentaram diferenças significativas.

No Brasil, não existem relatos sobre o uso do ovo em pó na alimentação de suínos e as tabelas nacionais e estrangeiras não fazem sequer referência sobre a sua composição e utilização. Assim, tendo conhecimento das propriedades nutricionais do ovo e sabendo da necessidade do leitão recém-desmamado em termos de exigências em nutrientes e qualidade dos ingredientes, torna-se pertinente a avaliação desse alimento alternativo.

Dessa forma, os objetivos dessa pesquisa foram determinar a composição química, os coeficientes de digestibilidade de nutrientes e os valores de energia e proteína digestíveis do ovo em pó e avaliar o desempenho e os componentes sanguíneos e plasmáticos de leitões recém-desmamados alimentados com dietas contendo níveis crescentes de ovo em pó em substituição ao plasma sangüíneo.

\section{Material e Métodos}

Os animais foram alojados em uma unidade de creche experimental com 20 gaiolas metálicas suspensas com área de $1,80 \mathrm{~m}^{2}$ cada uma $(1,50 \mathrm{x} 1,20 \mathrm{~m})$. As gaiolas eram providas de comedouro automático e bebedouro tipo chupeta. A área adjacente ao comedouro era compacta e aquela sob o bebedouro, metálica e vazada.

\section{Experimento I (ensaio de digestibilidade)}

Foram utilizados oito leitões (machos castrados e fêmeas), mestiços (Landrace x Large White) com peso médio de $16,0 \pm 1,5 \mathrm{~kg}$, distribuídos de forma homogênea em dois tratamentos com quatro repetições cada, sendo um animal por unidade experimental. Os tratamentos consistiram de uma ração referência, formulada para atender as exigências dos suínos na fase inicial, de acordo com Rostagno et al. (2000) e uma ração teste, onde o ovo em pó substituiu, na base na matéria natural, $30 \%$ da ração referência.

Foi utilizado o método de coleta parcial de fezes com a adição do óxido crômico $\left(\mathrm{Cr}_{2} \mathrm{O}_{3}\right)$ como indicador fecal, adicionado às rações na concentração de $0,5 \%$. Os animais foram submetidos a um período de adaptação de cinco dias às dietas experimentais, 
seguidos de cinco dias de coleta de fezes. Durante a fase de adaptação, foi quantificado diariamente o consumo voluntário de cada animal nos diferentes tratamentos, e o menor consumo serviu de base para a quantidade de ração fornecida durante o período experimental. Dessa forma, cada suíno recebeu uma quantidade diária de ração restrita por unidade de peso metabólico $\left(\mathrm{kg}^{0,75}\right)$.

As fezes foram coletadas duas vezes ao dia, diretamente do reto dos animais e, imediatamente, acondicionadas em sacos plásticos identificados e congeladas. Ao final do período, as amostras foram descongeladas, homogeneizadas e secas em estufa de $65^{\circ} \mathrm{C}$ por 72 horas. Em seguida, cada amostra foi pesada, moída e enviada ao laboratório para posteriores análises.

Determinou-se a concentração de óxido crômico nas rações e fezes por meio da técnica analítica experimental de fluorescência de raios $\mathrm{X}$ por dispersão de comprimento de onda (Nascimento Filho et al., 1997). Amostras do OP e das dietas e fezes foram analisadas em laboratório para a determinação da composição química e energia bruta, de acordo com a metodologia descrita por Silva et al. (1990). A partir da equação de Matterson (1965) foram calculados os valores dos coeficientes de digestibilidade aparente da matéria seca (CDapMS), energia bruta (CDapEB), proteína bruta (CDapPB), extrato etéreo (CDapEE) e os valores de proteína e energia digestíveis do OP. $O$ valor determinado de energia digestível foi utilizado para formulação das rações do Experimento II.

Experimento II (avaliação do desempenho e componentes plasmáticos e sangüíneos)

Foram utilizados 90 leitões (machos castrados e fêmeas), das raças Landrace, Large White ou mestiços dessas raças, desmamados aos $24 \pm 2$ dias de idade e com peso médio de $5,6 \pm 0,6 \mathrm{~kg}$. No período anterior ao desmame, todos os animais receberam a mesma ração à base de milho, farelo de soja e leite integral em pó e, a partir do desmame, os leitões foram imediatamente submetidos aos tratamentos.

O período experimental compreendeu duas fases, sendo uma a pré-inicial ( 1 a 14 dias pós-desmame) e outra a inicial ( 15 a 28 dias pós-desmame), em que os tratamentos consistiram de cinco dietas com níveis crescentes de substituição, 0, 25, 50, 75 e $100 \%$ da proteína do plasma sanguíneo (PS) de origem bovina pela proteína do ovo em pó (OP). Para isso, consideraram-se os valores analisados de proteína bruta do PS $(79,5 \%)$ e do OP $(53,5 \%)$, sendo que a somatória desses ingredientes nos diferentes tratamentos forneceu uma contribuição protéica nas dietas de 4,28\% na fase pré-inicial e de 2,14\% na fase inicial, quando os níveis foram reduzidos à metade. As dietas experimentais, todas isonutritivas, foram formuladas para atender as exigências dos suínos em cada fase de criação, baseando-se nas recomendações de Rostagno et al. (2000) (Tabela 1). Os leitões receberam ração e água à vontade durante todo o período experimental.

O experimento foi realizado com nove repetições por tratamento utilizando um delineamento em blocos completos casualizados, onde cada repetição foi composta por dois animais, totalizando 45 unidades experimentais. Para a formação dos blocos experimentais consideraram-se o peso inicial e a leitegada de origem. Foram feitas repetições no tempo de acordo com a disponibilidade de animais e instalação.

Foram avaliados ganho diário de peso, consumo diário de ração e conversão alimentar para as fases pré-inicial (1 a 14 dias), inicial (15 a 28 dias) e período total ( 1 a 28 dias pós-desmame). Ao final da última pesagem, os leitões foram submetidos a um período de jejum de 12 horas e, posteriormente, receberam, durante 30 minutos, uma alimentação à vontade e mais um jejum de cinco horas para a retirada de amostras de sangue através da veia cava anterior. O sangue de cada animal foi coletado em seringas de $10 \mathrm{~mL}$ para as análises dos componentes plasmáticos (uréia, proteína total, albumina, globulina, triglicérides e colesterol) e componentes sangüíneos (hematócrito e hemoglobina). As amostras foram imediatamente enviadas ao laboratório para serem analisadas.

Os dados obtidos foram submetidos à análise de variância PROG GLM do SAS (1996). Além disso, os graus de liberdade dos tratamentos foram decompostos em seus componentes individuais de regressão, pelos polinômios ortogonais. 
Tabela 1 - Composições percentual das dietas e níveis nutricionais calculados referente à fase de 1-14 dias pósdesmame

Table 1 - Percentual and calculated composition of the experimental diets in 1-14 days post weaned phase

\begin{tabular}{|c|c|c|c|c|c|c|c|c|c|c|c|}
\hline \multirow[b]{2}{*}{$\begin{array}{l}\text { Ingredientes } \\
\text { Ingredients }\end{array}$} & \multicolumn{5}{|c|}{$\begin{array}{l}\text { Níveis de substituição protéica } \\
\text { do PS pelo OP }(\%)\end{array}$} & \multirow[b]{2}{*}{$\begin{array}{l}\text { Ingredientes } \\
\text { Ingredients }\end{array}$} & \multicolumn{5}{|c|}{$\begin{array}{c}\text { Níveis de substituição protéica } \\
\text { do PS pelo OP }(\%)\end{array}$} \\
\hline & 0 & 25 & 50 & 75 & 100 & & 0 & 25 & 50 & 75 & 100 \\
\hline $\begin{array}{l}\text { Milho } \\
\text { Corn }\end{array}$ & 52,25 & 51,09 & 49,73 & 48,81 & $\overline{47,93}$ & $\begin{array}{l}\text { Sal } \\
\text { Salt }\end{array}$ & 0,20 & 0,20 & 0,20 & 0,20 & 0,20 \\
\hline $\begin{array}{l}\text { Farelo de soja } \\
\text { Soybean meal }\end{array}$ & 21,72 & 21,92 & 22,18 & 22,39 & 22,51 & $\begin{array}{l}\text { BHT } \\
\text { BHT }\end{array}$ & 0,01 & 0,01 & 0,01 & 0,01 & 0,01 \\
\hline $\begin{array}{l}\text { Ovo em pó } \\
\text { Spray-dried egg }\end{array}$ & - & 2,00 & 4,00 & 6,00 & 8,00 & $\begin{array}{l}\text { Suplemento vitamínico }{ }^{1} \\
\text { Vitamin mix }\end{array}$ & 0,10 & 0,10 & 0,10 & 0,10 & 0,10 \\
\hline $\begin{array}{l}\text { Plasma sanguíneo } \\
\text { Spray-dried plasma }\end{array}$ & 5,38 & 4,04 & 2,69 & 1,35 & - & $\begin{array}{l}\text { Suplemento mineral } \\
\text { Mineral mix }\end{array}$ & 0,10 & 0,10 & 0,10 & 0,10 & 0,10 \\
\hline $\begin{array}{l}\text { Soro de leite em pó } \\
\text { Dried whey }\end{array}$ & 10,00 & 10,00 & 10,00 & 10,00 & 10,00 & $\begin{array}{l}\text { Níveis nutricionais calcu } \\
\text { Calculated nutricional level }\end{array}$ & ulados & & & & \\
\hline $\begin{array}{l}\text { Lactose } \\
\text { Lactose }\end{array}$ & 5,00 & 5,00 & 5,00 & 5,00 & 5,00 & $\begin{array}{l}\text { Proteína bruta, \% } \\
\text { Crude protein }\end{array}$ & 20,00 & 20,00 & 20,00 & 20,00 & $\overline{20,00}$ \\
\hline $\begin{array}{l}\text { Açúcar } \\
\text { Sugar }\end{array}$ & 2,00 & 2,00 & 2,00 & 2,00 & 2,00 & Energia digestível, & & & & & \\
\hline $\begin{array}{l}\text { Calcário } \\
\text { Limestone }\end{array}$ & 0,74 & 0,76 & 0,78 & 0,79 & 0,81 & $\begin{array}{l}\mathrm{kcal} / \mathrm{kg} \\
\text { Digestible energy }\end{array}$ & 3.385 & 505 & 3.385 & .50. & 3.385 \\
\hline $\begin{array}{l}\text { Fosfato bicálcico } \\
\text { Dicalcium phosphate }\end{array}$ & 1,81 & 1,77 & 1,74 & 1,70 & 1,66 & $\begin{array}{l}\text { Fósforo total, } \% \\
\text { Total phosphorus }\end{array}$ & 0,67 & 0,67 & 0,67 & 0,67 & 0,67 \\
\hline $\begin{array}{l}\text { Caulim } \\
\text { Inert material }\end{array}$ & - & 0,31 & 0,78 & 0,89 & 0,96 & $\begin{array}{l}\text { Cálcio, \% } \\
\text { Calcium }\end{array}$ & 0,90 & 0,90 & 0,90 & 0,90 & 0,90 \\
\hline $\begin{array}{l}\text { Óxido de zinco, } 78 \% \\
\text { Zinc oxide }\end{array}$ & 0,34 & 0,34 & 0,34 & 0,34 & 0,34 & $\begin{array}{l}\text { Lisina, \% } \\
\text { Lysine }\end{array}$ & 1,35 & 1,35 & 1,35 & 1,35 & 1,35 \\
\hline $\begin{array}{l}\text { L-lisina. } \mathrm{HCl}, 78 \% \\
\text { L-lysine }\end{array}$ & 0,22 & 0,23 & 0,25 & 0,27 & 0,29 & $\begin{array}{l}\text { Metionina, \% } \\
\text { Methionine }\end{array}$ & 0,40 & 0,40 & 0,40 & 0,40 & 0,40 \\
\hline $\begin{array}{l}\text { DL-metionina } \\
\text { DL-methionine }\end{array}$ & 0,08 & 0,07 & 0,06 & 0,05 & 0,04 & $\begin{array}{l}\text { Treonina, \% } \\
\text { Threonine }\end{array}$ & 0,84 & 0,84 & 0,83 & 0,82 & 0,81 \\
\hline $\begin{array}{l}\text { Cloreto de colina } 60 \% \\
\text { Choline cloride }\end{array}$ & 0,05 & 0,05 & 0,05 & 0,05 & 0,05 & $\begin{array}{l}\text { Triptofano, } \% \\
\text { Tryptophan }\end{array}$ & 0,25 & 0,25 & 0,25 & 0,24 & 0,24 \\
\hline
\end{tabular}

${ }^{1}$ Cada kg de ração continha (Provided per kg of diet): vit. A, $8.000 \mathrm{UI}$; vit. $\mathrm{D}_{3}, 1.500 \mathrm{UI}$; vit. E, $18 \mathrm{mg}$; vit. $\mathrm{K}_{3}, 2 \mathrm{mg} ;$ vit. $\mathrm{B}_{1}, 1,5 \mathrm{mg} ;$ vit. $\mathrm{B}_{2}$, $4 \mathrm{mg}$; vit. $\mathrm{B}_{6}, 1,5 \mathrm{mg}$; vit. $\mathrm{B}_{12}, 18 \mathrm{mg}$; ácido fólico (folic acid) $0,4 \mathrm{mg}$; biotina (biotin), $0,1 \mathrm{mg}$; pantotenato de cálcio, $15 \mathrm{mg}$; niacina (niacin), $30 \mathrm{mg}$; Se, $0,12 \mathrm{mg}$.

${ }^{2}$ Cada kg de ração continha (Provided per kg of diet): Mn, 45 mg; Cu, 15 mg; Zn, 80 mg; Fe, 88 mg; I, 1 mg. 
Tabela 2 - Composições percentual das dietas e níveis nutricionais calculados referentes à fase de 15-28 dias pósdesmame

Table 2 - Percentual and calculated composition of the experimental diets in 15-28 days post weaned phase

\begin{tabular}{|c|c|c|c|c|c|c|c|c|c|c|c|}
\hline \multirow[b]{2}{*}{$\begin{array}{l}\text { Ingredientes } \\
\text { Ingredients }\end{array}$} & \multicolumn{5}{|c|}{$\begin{array}{c}\text { Níveis de substituição protéica } \\
\text { do PS pelo OP }(\%)\end{array}$} & \multirow[b]{2}{*}{$\begin{array}{l}\text { Ingredientes } \\
\text { Ingredients }\end{array}$} & \multicolumn{5}{|c|}{$\begin{array}{c}\text { Níveis de substituição protéica } \\
\text { do PS pelo OP }(\%)\end{array}$} \\
\hline & 0 & 25 & 50 & 75 & 100 & & 0 & 25 & 50 & 75 & $\overline{100}$ \\
\hline $\begin{array}{l}\text { Milho } \\
\text { Corn }\end{array}$ & 58,06 & 57,66 & 57,23 & 56,86 & $\overline{56,47}$ & $\begin{array}{l}\mathrm{BHT} \\
\mathrm{BHT}\end{array}$ & 0,01 & 0,01 & 0,01 & 0,01 & $\overline{0,01}$ \\
\hline $\begin{array}{l}\text { Farelo de soja } \\
\text { Soybean meal }\end{array}$ & 25,54 & 25,63 & 25,70 & 25,78 & 25,85 & $\begin{array}{l}\text { Suplemento vitamínico }{ }^{1} \\
\text { Vitamin mix }\end{array}$ & 0,10 & 0,10 & 0,10 & 0,10 & 0,10 \\
\hline $\begin{array}{l}\text { Ovo em pó } \\
\text { Spray-dried egg }\end{array}$ & - & 1,00 & 2,00 & 3,00 & 4,00 & $\begin{array}{l}\text { Suplemento mineral } \\
\text { Mineral mix }\end{array}$ & 0,10 & 0,10 & 0,10 & 0,10 & 0,10 \\
\hline $\begin{array}{l}\text { Plasma sangüíneo } \\
\text { Spray-dried plasma }\end{array}$ & 2,69 & 2,02 & 1,35 & 0,68 & - & $\begin{array}{l}\text { Níveis nutricionais calcu } \\
\text { Calculated nutricional level }\end{array}$ & ulados & & & & \\
\hline $\begin{array}{l}\text { Soro de leite em pó } \\
\text { Dried whey }\end{array}$ & 5,00 & 5,00 & 5,00 & 5,00 & 5,00 & $\begin{array}{l}\text { Proteína bruta, \% } \\
\text { Crude protein }\end{array}$ & 19,50 & 19,50 & 19,50 & 19,50 & 19,50 \\
\hline $\begin{array}{l}\text { Lactose } \\
\text { Lactose } \\
\text { Açúcar }\end{array}$ & 2,00 & 2,00 & 2,00 & 2,00 & 2,00 & $\begin{array}{l}\text { Energia digestível, } \\
\mathrm{kcal} / \mathrm{kg} \\
\text { Digestible energy }\end{array}$ & 3.360 & 3.370 & 3.375 & 3.380 & 3.390 \\
\hline $\begin{array}{l}\text { Sugar } \\
\text { Calcário }\end{array}$ & 0,77 & 0,77 & 0,78 & 0,79 & 0,80 & $\begin{array}{l}\text { Fósforo total, } \% \\
\text { Total phosphorus }\end{array}$ & 0,68 & 0,68 & 0,68 & 0,68 & 0,68 \\
\hline $\begin{array}{l}\text { Limestone } \\
\text { Fosfato bicálcico } \\
\text { Dicalcium phosphate }\end{array}$ & 1,89 & 1,87 & 1,84 & 1,83 & 1,81 & $\begin{array}{l}\text { Cálcio, \% } \\
\text { Calcium }\end{array}$ & 0,90 & 0,90 & 0,90 & 0,90 & 0,90 \\
\hline $\begin{array}{l}\text { Óxido de zinco, } 78 \% \\
\text { Zinc oxide }\end{array}$ & 0,30 & 0,30 & 0,30 & 0,30 & 0,30 & $\begin{array}{l}\text { Lisina, \% } \\
\text { Lysine }\end{array}$ & 1,20 & 1,20 & 1,20 & 1,20 & 1,20 \\
\hline $\begin{array}{l}\mathrm{L} \text {-lisina. } \mathrm{HCl}, 78 \% \\
\text { L-lysine }\end{array}$ & 0,15 & 0,16 & 0,17 & 0,18 & 0,19 & $\begin{array}{l}\text { Metionina, \% } \\
\text { Methionine }\end{array}$ & 0,35 & 0,35 & 0,35 & 0,35 & 0,35 \\
\hline $\begin{array}{l}\text { DL-metionina } \\
\text { DL-methionine }\end{array}$ & 0,04 & 0,03 & 0,03 & 0,02 & 0,02 & $\begin{array}{l}\text { Treonina, } \% \\
\text { Threonine }\end{array}$ & 0,79 & 0,79 & 0,78 & 0,78 & 0,77 \\
\hline $\begin{array}{l}\text { Cloreto de colina } 60 \% \\
\text { Choline cloride }\end{array}$ & 0,05 & 0,05 & 0,05 & 0,05 & 0,05 & $\begin{array}{l}\text { Triptofano, } \% \\
\text { Tryptophan }\end{array}$ & 0,24 & 0,24 & 0,24 & 0,24 & 0,23 \\
\hline $\begin{array}{l}\text { Sal } \\
\text { Salt }\end{array}$ & 0,30 & 0,30 & 0,30 & 0,30 & 0,30 & & & & & & \\
\hline
\end{tabular}

1 Cada kg de ração continha (Provided per kg of diet): vit. A, $8.000 \mathrm{UI}$; vit. $\mathrm{D}_{3}, 1.500 \mathrm{UI}$; vit. $\mathrm{E}, 18 \mathrm{mg}$; vit. $\mathrm{K}_{3}, 2 \mathrm{mg} ;$ vit. $\mathrm{B}_{1}, 1,5 \mathrm{mg} ;$ vit. $\mathrm{B}_{2}, 4 \mathrm{mg}$; vit. $\mathrm{B}_{6}, 1,5 \mathrm{mg}$; vit. $\mathrm{B}_{12}, 18 \mathrm{mg}$; ácido fólico (folic acid) $0,4 \mathrm{mg}$; biotina (biotin), $0,1 \mathrm{mg}$; pantotenato de cálcio, $15 \mathrm{mg}$; niacina (niacin), $30 \mathrm{mg} ; \mathrm{Se}, 0,12 \mathrm{mg} .{ }^{2}$ Cada kg de ração continha (Provided per kg of diet): $\mathrm{Mn}, 45 \mathrm{mg} ; \mathrm{Cu}, 15 \mathrm{mg} ; \mathrm{Zn}, 80 \mathrm{mg} ; \mathrm{Fe}, 88 \mathrm{mg} ; \mathrm{I}$, $1 \mathrm{mg}$.

\section{Resultados e Discussão}

\section{Experimento $I$}

\section{Ensaio de digestibilidade}

A composição química e energia bruta do OP encontra-se na Tabela 3. Os valores de proteína bruta $(53,56 \%)$ e de energia bruta $(5.897 \mathrm{kcal} / \mathrm{kg})$ determinados para o OP no presente trabalho são diferentes dos valores apresentados recentemente por Hannas et al (2001), de 48,62\% e $6.201 \mathrm{kca} / \mathrm{kg}$, respectivamente, para proteína bruta e energia bruta. Essas diferenças encontradas podem ser explicadas pela falta de padronização no processamento a que esses produtos são submetidos. Bertol \& Ludke (1999) afirmaram que um processamento inadequado pode causar alteração na disponibilidade dos nutrientes, variando, assim, o valor nutricional do alimento. Além disso, possivelmente em função do tamanho de ovos e/ou perda das frações gema ou clara de ovos quebrados, pode haver alteração nos conteúdos de proteína e gordura, o que explicaria os resultados variados. 
Comparando com os valores protéicos de outras fontes utilizadas em dietas complexas para leitões em fase de creche, verifica-se que o conteúdo de proteína bruta do OP foi superior ao do leite em pó desnatado $(33,65 \%)$, mas inferior ao plasma sangüíneo $(69,70 \%)$ (Rostagno et al., 2000). Esse dado é importante, admitindo que a maioria das dietas formuladas para suínos baseia-se no conteúdo de proteína bruta do ingrediente, além de a proteína do ovo apresentar elevado valor biológico, normalmente referido como a de valor equivalente a 100 para o ser humano.

Os coeficientes de digestibilidade aparente dos nutrientes do OP são apresentados na Tabela 4. De maneira geral, os coeficientes de digestibilidade aparente de nutrientes determinados para o OP apresentaram-se elevados quando comparados a valores encontrados na literatura brasileira para outros ingredientes protéicos como farinha de peixe (Battisti et al., 1985), farinha de carne e ossos (Serrano, 1989), leite desnatado em pó (Moreira et al., 1994) e plasma desidratado (Pupa et al., 1999).

Tabela 3 - Composição química e valor energético do ovo em pó, expresso na matéria natural (Experimento I)

Tabela 3 - Chemical composition and energy values of spraydried egg, in natural matter (Experiment I)

Matéria seca (Dry matter), \% 92,70

Proteína bruta (Crude protein), \% $\quad 53,56$

Leucina (Leucine), \% $\quad 4,77$

Lisina (Lysine), \% $\quad 4,26$

Valina(Valine), $\% \quad 3,41$

Arginina (Arginine), \% $\quad 3,34$

Fenilalanina (Phenilalanine), $\% \quad 3,18$

Isoleucina (Isoleucine), \% $\quad 2,77$

Treonina (Threonine), \% 2,69

Metionina (Methionine), \% 2,53

Histidina (Histidine), \% $\quad 1,56$

Energia bruta (Gross energy), kcal/kg $\quad 5.897$

Extrato etéreo (Crude fat), \% $\quad 22,15$

Matéria mineral (Mineral matter), \% $\quad 5,74$

Cálcio (Calcium), \% $\quad 0,26$

Fósforo (Phosphorus), \% $\quad 0,54$

Sódio (Sodium), \% $\quad 0,24$

Potássio (Potassium), \% $\quad 0,27$

Magnésio (Magnesium), ppm 600

Zinco (Zinc), ppm 40

Ferro (Iron), ppm $\quad 40$

Cobre (Cupper), ppm 3
Para comparação dos valores de coeficientes de digestibilidade, é importante ressaltar que a digestibilidade das várias frações do alimento pode ser influenciada pela idade e pelo peso dos animais (Fialho et al., 1982 a, b). O ensaio de digestibilidade do presente estudo foi realizado com leitões mais velhos e de maior peso vivo que os anteriormente referidos na literatura, nos quais foram utilizados animais recém-desmamados. Além disso, a digestibilidade dos nutrientes de alimentos processados depende, também, da própria composição do alimento, do tipo de processamento, do tempo e temperatura de aquecimento e do nível de inclusão do alimento na ração, entre outros (Moreira et al., 1994).

A energia digestível do OP de $5.140 \mathrm{kcal} / \mathrm{kg}$ determinada nesse trabalho foi inferior àquela encontrada por Hannas et al. (2001) de $5.390 \mathrm{kcal} / \mathrm{kg}$, enquanto a proteína digestível foi superior $(43,90 \%$ vs $40,27 \%$ ). Recentemente, Harmon et al. (2001) determinaram o valor de energia metabolizável do OP para leitões recém-desmamados como sendo de $4.700 \mathrm{kcal} / \mathrm{kg}$.

No geral, o valor determinado de energia digestível do OP foi superior aos valores de todos os outros alimentos utilizados como fonte de energia para suínos, com exceção de óleos e gorduras. Harmon et al. (2001) destacaram ser esta uma importante característica do OP, chegando a apresentar $37 \%$ mais energia do que o milho, principal fonte energética para os suínos.

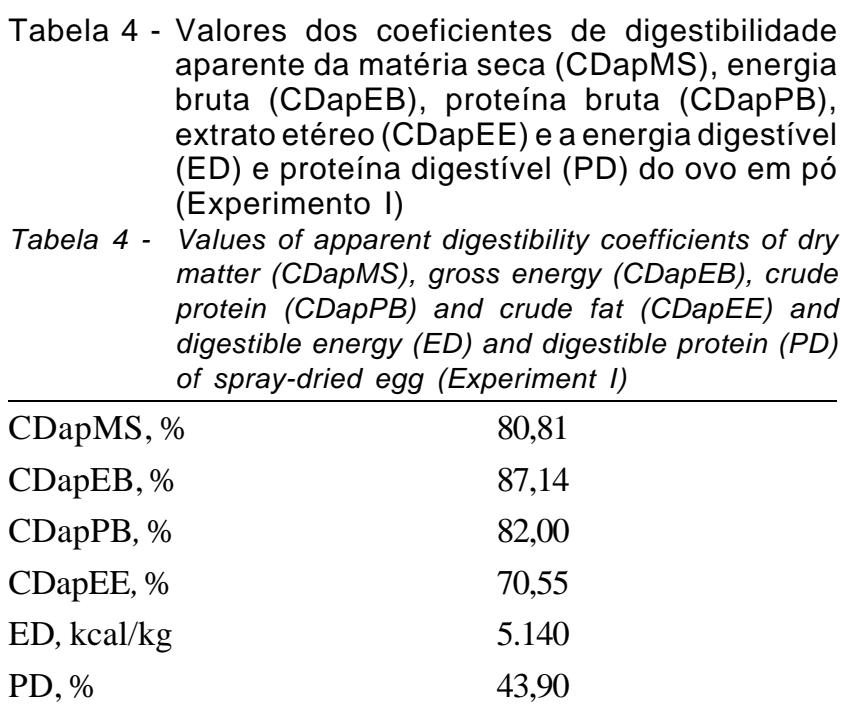




\section{Experimento II}

\section{Características de desempenho}

De acordo com os resultados apresentados na Tabela 5, observa-se que os níveis de inclusão da proteína do $\mathrm{OP}$ em substituição à proteína do $\mathrm{PS}$ não influenciaram $(\mathrm{P}>0,05)$ as variáveis de desempenho durante a fase pré-inicial de 1 a 14 dias pós-desmame. No entanto, mesmo sem diferenças significativas, verificou-se que a completa substituição da proteína do PS pela proteína do OP (tratamento $100 \%$ ) resultou no menor GDP e pior CA, sendo que os melhores resultados alcançados foram com $25 \mathrm{e}$ $50 \%$ de contribuição protéica de cada ingrediente. Como nesta fase a inclusão do OP foi de até $8 \%$, isto significa que a inclusão de níveis em até $4 \%$ não prejudica o desempenho dos animais.

Estes resultados referentes a fase de 1 a 14 dias pós-desmame, concordam com os relatos de Jaen et al. (2001) e Harmon et al. (2000), que encontraram melhor resposta para a combinação de PS com OP do que para apenas a utilização do OP. Na realidade, Jaen et al. (2001) verificaram que a substituição de

Tabela 5 - Desempenho dos leitões para as variáveis ganho diário de peso (GDP), consumo diário de ração (CDR), conversão alimentar (CA) (Experimento II)

Tabela 5 - Performance of pigs for variables daily weight gain $(G D P)$, daily feed intake (CDR), feed:gain ratio (CA) (Experiment II)

\begin{tabular}{|c|c|c|c|c|c|c|}
\hline \multirow[t]{2}{*}{$\begin{array}{l}\text { Variáveis } \\
\text { Variables }\end{array}$} & \multicolumn{6}{|c|}{$\begin{array}{l}\text { Níveis de substituição protéica } \\
\text { do PS pelo OP, \% } \\
\text { Replacement level of PS by OP, \% }\end{array}$} \\
\hline & 0 & 25 & 50 & 75 & 100 & $\mathrm{CV}^{\mathrm{b}}$ \\
\hline \multicolumn{7}{|c|}{$1 \mathrm{a} 14$ dias } \\
\hline GDP, $\mathrm{kg}$ & 0,175 & 0,185 & 0,190 & 0,161 & 0,150 & 22,3 \\
\hline CDR, kg & 0,313 & 0,313 & 0,338 & 0,311 & 0,311 & 12,8 \\
\hline $\mathrm{CA}$ & 1,83 & 1,78 & 1,82 & 2,07 & 2,13 & 18,2 \\
\hline \multicolumn{7}{|c|}{15 a 28 dias } \\
\hline $\mathrm{GDP}, \mathrm{kg}^{\mathrm{a}}$ & 0,576 & 0,531 & 0,546 & 0,491 & 0,446 & $\overline{10,9}$ \\
\hline $\mathrm{CDR}, \mathrm{kg}^{\mathrm{a}}$ & 0,890 & 0,840 & 0,838 & 0,770 & 0,722 & 10,2 \\
\hline $\mathrm{CA}$ & 1,55 & 1,60 & 1,54 & 1,57 & 1,63 & 6,0 \\
\hline \multicolumn{7}{|c|}{1 a 28 dias } \\
\hline $\mathrm{GDP}, \mathrm{kg}^{\mathrm{a}}$ & 0,375 & 0,357 & 0,368 & 0,326 & 0,298 & 11,2 \\
\hline $\mathrm{CDR}, \mathrm{kg}^{\mathrm{a}}$ & 0,615 & 0,581 & 0,608 & 0,555 & 0,528 & 8 , \\
\hline $\mathrm{CA}$ & 1,65 & 1,65 & 1,66 & 1,71 & 1,80 & 7,2 \\
\hline
\end{tabular}

a Efeito linear $(P<0,01)$ (Linear effect $[P<0.01])$.

b Coeficiente de variação (\%) (Coefficient of variation).
$50 \%$ do PS por OP resultou em melhor GDP e CDR em relação a $100 \%$ de substituição. Já Harmon et al. (2000) ofereceram a leitões desmamados aos 16 dias de idade quatro combinações de proteína do OP e do PS durante um período de 24 dias pós-desmame e encontraram maiores GDP e CDR para os animais que receberam as dietas com 0 e 33\% de proteína de OP em comparação aos animais que receberam as dietas com 66 e 100\% de proteína de OP.

Nessmith et al. (1996) ofereceram a leitões uma combinação, com base no conteúdo de lisina, de 5,0\% de PS $+4,95 \%$ de OP e $2,5 \%$ de PS $+9,9 \%$ de OP e observaram CDR inferior apenas quando a inclusão de OP foi maior.

Mesmo com o OP promovendo pior desempenho dos animais, é interessante relatar que Nessmith et al. (1996) e Harmon et al. (2000) não observaram diferenças entre as variáveis de desempenho dos animais quando estes passaram a receber uma dieta basal após a alimentação com OP, verificando, então, que os animais não foram prejudicados a ponto de comprometer seus desempenhos nas fases posteriores.

Para a fase inicial, correspondente ao período de 15 a 28 dias pós-desmame, foram observadas reduções lineares $(\mathrm{P}<0,01)$ do GDP (GDP $=0,57784$ $\left.0,00129 \mathrm{X}, \mathrm{r}^{2}=0,73\right)$ e $\mathrm{CDR}(\mathrm{CDR}=0,89302$ $\left.0,00162 X, r^{2}=0,73\right)$, em que $X$ é a $\%$ de substituição da proteína do PS pela proteína do OP. Para a variável CA não foi detectada diferença significativa $(\mathrm{P}>0,05)$. Notou-se, de acordo com o comportamento linear, que, para cada $1 \%$ de inclusão do OP, os animais reduziram em 1,29 g o GDP e em 1,62 g o CDR. Vale lembrar que a inclusão do OP nesta fase foi reduzida à metade, atingindo o nível de até 4\%; na fase anterior, este nível não prejudicou o desempenho dos animais.

Para o período total (1 a 28 dias), foram também observadas reduções lineares $(\mathrm{P}<0,01)$ para as variáveis GDP $\left(\mathrm{GDP}=0,38191-0,00074 \mathrm{X}, \mathrm{r}^{2}=0,73\right)$ e CDR $\left(C D R=0,61729-0,00079 X, r^{2}=0,74\right)$, à medida que se aumentava a \% de substituição da proteína do PS pela proteína do OP. Entretanto, para a CA, não foi observado efeito significativo $(\mathrm{P}>0,05)$, mas sim forte tendência $(\mathrm{P}<0,06)$ de piora linear com a inclusão de OP.

Os trabalhos na literatura indicam que o desempenho dos animais nas fases posteriores ao desmame tem forte relação com os resultados obtidos em função das dietas oferecidas nos primeiros 14 dias pós-desmame (de Rodas et al., 1995; Hansen et al., 
1993; Mahan \& Lepine, 1991). Dessa forma, possivelmente, as diferenças entre os tratamentos encontradas para a segunda fase de criação (15 a 28 dias) e período total (1a 28 dias) podem ser reflexo de que, na primeira fase (1 a 14 dias), os animais foram prejudicados, ao receberem a proteína do OP, em substituição à proteína do PS.

Existem alguns fatores que podem explicar o pior desempenho dos animais que receberam maiores proporções de OP em suas dietas e, um deles, é a pior palatabilidade do OP em relação ao PS. Em grande parte dos dados encontrados na literatura, o prejuízo no desempenho dos leitões que receberam o OP em suas dietas foi atribuído a menor consumo de ração (Nessmith et al., 1996; Norin et al., 1998; Harmon et al., 2000; Jaen et al., 2000). Em contrapartida, Ermer et al. (1994) testaram a preferência de leitões que podiam escolher entre a dieta contendo PS ou leite desnatado em pó e o consumo foi maior em $200 \mathrm{~g} /$ dia para a dieta com PS. Resultados semelhantes foram encontrados por Hansen et al. (1993) e Butolo et al. (1999).

Assim, a pior palatabilidade apresentada pelo OP, associada à melhor palatabilidade do PS, pode ter promovido menor consumo de ração e, conseqüentemente, menor ganho de peso dos animais que receberam maiores quantidades de OP em suas dietas, refletindo no desempenho inferior observado.

Outra possibilidade para explicar o pior desempenho dos leitões poderia ser atribuída ao processamento por spray-dry e o conteúdo de glicose presente na gema do ovo. De acordo com Aguirre et al. (1979) e Berquist (1994) pode ocorrer a interação glicoseproteína (reação de Maillard), que é acelerada pela ação do calor e pela presença da água. Como o grupo $\mathrm{NH}_{2}$ do carbono épsilon do aminoácido lisina (primeiro limitante para suínos) está envolvido nesta reação, o resultado seria decréscimo do valor biológico da proteína e, conseqüentemente, pior desempenho dos animais alimentados com OP. Por outro lado, os mesmos autores comentaram que nem os pré-tratamentos, como a pasteurização e a secagem em si, se corretamente executados, parecem diminuir o valor biológico. Concordando com esta afirmação, Jaen et al. (2001) observaram que o OP pasteurizado ou não pasteurizado, substituindo 50 e $100 \%$ de PS, não afetou o GDP $(\mathrm{P}>0,01)$ de leitões desmamados aos 20 dias de idade.

\section{Componentes plasmáticos e sangüíneos}

Os níveis de inclusão da proteína do OP em substituição à proteína do PS não influenciaram
( $\mathrm{P}>0,05)$ nenhuma das variáveis dos componentes plasmáticos (Tabela 6). Entretanto, para a componente uréia (UR) no plasma dos leitões, observou-se forte tendência $(\mathrm{P}<0,07)$ de redução linear $\left(\mathrm{UR}=31,48889-0,47422 \mathrm{X}, \mathrm{r}^{2}=0,57\right)$, à medida que se aumentou a inclusão de OP nas dietas.

A uréia é o produto final do catabolismo dos aminoácidos dos mamíferos e é produzida, de maneira geral, quando a dieta é rica em proteína e os aminoácidos ingeridos excedem a necessidade corporal para a síntese protéica ou durante o jejum quando as proteínas celulares são usadas como fonte de energia para o corpo (Nelson \& Cox, 2000). Na nutrição animal, outro motivo é quando a dieta é inadequada em algum dos aminoácidos essenciais e a síntese de proteína não ocorre em velocidade igual à obtida quando esse aminoácido está disponível em níveis adequados (Penz Jr. \& Viola, 1998). Dessa forma, há um aumento da concentração de uréia no plasma, devido a um imbalanço de aminoácidos (Brow \& Cline, 1974; Coma et al., 1995) ou ao consumo de uma proteína de má qualidade (Brow \& Cline, 1974).

Assim, a redução de uréia observada nos tratamentos com maior inclusão de OP, em comparação ao tratamento com apenas o PS (tratamento 0\%), pode refletir em uma utilização mais eficiente do nitrogênio total e melhor equilíbrio dos aminoácidos desse ingrediente, indicando ser uma proteína de alto valor biológico. Contudo, essa afirmação é questionável, pois melhor aproveitamento dos aminoácidos deveria resultar em melhor desempenho dos animais, o que não foi comprovado no presente trabalho para o período total.

Quanto ao componente proteína total (PT), houve tendência $(\mathrm{P}<0,08)$ de redução linear $(\mathrm{PT}=5,59555$ $\left.-0,03079 X, r^{2}=0,54\right)$, com o aumento dos níveis de inclusão da proteína do $\mathrm{OP}$, em detrimento à proteína do PS, o que não foi observado $(\mathrm{P}>0,05)$ para os componentes plasmáticos albumina, globulina e para a relação albumina/globulina.

Moderada deficiência de proteína ou de um único aminoácido da dieta pode provocar queda no conteúdo de proteínas séricas, principalmente devido à redução da albumina (Pond \& Maner, 1974, citados por Miyada, 1987). Segundo esses mesmos autores, a concentração plasmática dessas variáveis pode ser critério para avaliar a nutrição protéica de suínos.

Dessa forma, os resultados obtidos para os componentes uréia e proteínas globulares (proteína total, 
albumina, globulina e relação albumina/globulina) são contraditórios, pois o aumento da inclusão do OP causou redução nos níveis de uréia, supondo melhor balanço da proteína e aproveitamento desse ingrediente pelos animais. Entretanto, concomitantemente, houve também redução das proteínas globulares, o que é indicativo de menor disponibilidade de aminoácidos para a síntese das mesmas.

Também foi possível observar tendência $(\mathrm{P}<0,08)$ de aumento linear do conteúdo de triglicérides $\left(\mathrm{TG}=28,5333+0,85076 \mathrm{X}, \mathrm{r}^{2}=0,37\right)$, à medida que se aumentava a inclusão de OP. De acordo com Miyada (1987), há fortes evidências de que o nível de triglicérides no plasma seja influenciado pelo nível de energia da ração. Dessa forma, com as rações sendo isocalóricas, não devem haver diferenças significativas entre os tratamentos. Entretanto, a concentração de triglicérides do plasma de leitões que receberam a dieta só com OP (100\%) foi $27,5 \%$ superior ao daqueles que receberam a dieta sem OP $(0 \%)$.

O nível de colesterol manteve-se similar entre os tratamentos. Contudo, Danielson et al. (1989) destacaram que suínos adultos alimentados com dietas contendo $10,6 \%$ de gema em pó, durante 56 dias, apresentaram aumento significativo (43\%) do colesterol no dia 28, mantendo-se elevado até o dia 56.

O nível de colesterol no plasma dos animais pode ser controlado pelo estado nutricional, pelos teores dietéticos de gordura e fatores hormonais (Mendonça Jr., 1996), sendo que um organismo possuidor de controle enzimático normal, mediante altas ingestões de colesterol, promove a redução de sua síntese orgânica, mantendo os níveis de colesterol estáveis (Naber, 1990). Assim, o aumento do colesterol no plasma está mais relacionado com as quantidades de energia e gordura saturada ingeridas do que da própria ingestão do colesterol em si (Mendonça Jr., 1996).

Tabela 6 - Valores médios dos tratamentos para os componentes plasmáticos e sangüíneos (Experimento II)

Table 6 - Mean values of trataments for plasma and blood components (Experiment II)

\begin{tabular}{|c|c|c|c|c|c|c|}
\hline & \multicolumn{6}{|c|}{$\begin{array}{c}\text { Níveis de substituição protéica do PS pelo OP, \% } \\
\text { Replacement level of PS by OP, \% }\end{array}$} \\
\hline & 0 & 25 & 50 & 75 & 100 & $\mathrm{CV}^{\mathrm{a}}$ \\
\hline $\begin{array}{l}\text { Componentes plasmáticos } \\
\text { Plasma components }\end{array}$ & & & & & & \\
\hline $\begin{array}{l}\text { Uréia, } \mathrm{mg} / \mathrm{dL} \\
\text { Urea }\end{array}$ & 33,94 & 29,00 & 27,67 & 24,11 & 30,06 & 18,14 \\
\hline $\begin{array}{l}\text { Proteína total, g/dL } \\
\text { Total protein }\end{array}$ & 5,53 & 5,61 & 5,51 & 4,79 & 5,33 & 4,07 \\
\hline $\begin{array}{l}\text { Albumina, g/dL } \\
\text { Albumin }\end{array}$ & 3,71 & 3,72 & 3,67 & 3,22 & 3,66 & 5,99 \\
\hline $\begin{array}{l}\text { Globulina, g/dL } \\
\text { Globulin }\end{array}$ & 1,82 & 1,89 & 1,84 & 1,57 & 1,67 & 13,08 \\
\hline $\begin{array}{l}\text { Relação albumina/globulina } \\
\text { Albumin/globulin ratio }\end{array}$ & 2,12 & 2,06 & 2,03 & 1,89 & 2,29 & 15,44 \\
\hline $\begin{array}{l}\text { Triglicérides, } \mathrm{mg} / \mathrm{dL} \\
\text { Triglicerides }\end{array}$ & 28,94 & 32,94 & 26,83 & 30,33 & 36,89 & 25,69 \\
\hline $\begin{array}{l}\text { Colesterol, } \mathrm{mg} / \mathrm{dL} \\
\text { Cholesterol }\end{array}$ & 91,72 & 87,17 & 91,67 & 74,06 & 87,89 & 11,49 \\
\hline $\begin{array}{l}\text { Componentes sangüíneos } \\
\text { Blood components }\end{array}$ & & & & & & \\
\hline $\begin{array}{l}\text { Hemoglobina, g/dL } \\
\text { Hemoglobin }\end{array}$ & 11,93 & 12,92 & 12,01 & 10,26 & 12,09 & 18,54 \\
\hline $\begin{array}{l}\text { Hematócrito, \% } \\
\text { Hematocrit }\end{array}$ & 38,19 & 35,10 & 38,04 & 32,07 & 37,89 & 8,44 \\
\hline
\end{tabular}

R. Bras. Zootec., v.32, n.6, p.1901-1911, 2003 (Supl. 2) 
Quanto aos componentes sangüíneos, não houve qualquer influência $(\mathrm{P}>0,05)$ da substituição da proteína do PS pela proteína do OP sobre a concentração de hemoglobina e hematócrito. De acordo com Pond \& Maner (1974), citados por Miyada (1987), os níveis de hemoglobina e hematócrito são indicadores do estado nutricional dos suínos quanto ao nutriente ferro. Como o OP utilizado no presente trabalho apresentou baixo conteúdo de ferro, determinado previamente no Experimento I, justificam-se os valores similares dos componentes sangüíneos entre os tratamentos. Há também indicações de que o hematócrito possa estar relacionado ao nível de lisina da ração (Miyada, 1987). Dessa forma, considerando que ambos os ingredientes (OP e PS) que variaram nas dietas são fontes ricas em lisina e todas as dietas foram isolisínicas, os níveis de hematócrito permaneceram estáveis.

\section{Conclusões}

O ovo em pó é um alimento que apresenta uma composição química com alto valor de proteína bruta $(53,56 \%)$ e energia bruta $(5.897 \mathrm{kcal} / \mathrm{kg})$, além de altos coeficientes de digestibilidade de nutrientes e valores de proteína digestível $(43,91 \%)$ e energia digestível $(5.159 \mathrm{kcal} / \mathrm{kg})$ Esses resultados demonstraram que o OP pode não somente ser utilizado como fonte protéica de qualidade, mas também contribuir com o valor energético na alimentação de leitões em fase de creche.

Esse ingrediente pode substituir completamente o plasma sangüíneo, sem afetar o desempenho dos animais na fase pré-inicial de 1 a 14 dias pósdesmame. Entretanto, para a fase de 15 a 28 dias, a combinação em diferentes proporções, ou, a substituição protéica completa do plasma sanguíneo pelo ovo em pó, prejudicou o desempenho dos animais, refletindo, assim, em pior desempenho no período total (1 a 28 dias).

Os componentes sangüíneos e plasmáticos dos leitões não foram alterados em função do fornecimento de dietas contendo diferentes proporções de proteína do ovo em pó em substituição à proteína do plasma sanguíneo.

Em função dos resultados obtidos, não foi viável a substituição do plasma sangüíneo pelo ovo em pó nas dietas de leitões durante a fase de creche.

\section{Literatura Citada}

AGUIRRE, J.M.; TRAVAGLINI, D.A.; SILVEIRA, E.T.F. Desidratação de ovos. Boletim do Instituto de Tecnologia de Alimentos, 1979. p.261-287.

BERQUIST, D.H. Egg dehydration. In: STADELMAN, W.J.; COTTERILL, O.J. (Eds.). Egg science and technology. New York: Food Products Press, 1994. p.335-76.

BERTOL, T.M.; LUDKE, J.V. Determinação dos valores de energia e do balanço de nitrogênio de alguns alimentos para leitões na fase inicial. Revista da Sociedade Brasileira de Zootecnia, v.28, n.6, p.1279-1287, 1999.

BROWN, J.A.; CLINE, T.R. Urea excretion in the pig: an indicator of protein quality and amino acid requirements. Journal of Nutrition, v.104, p.542-551, 1974.

BUTOLO, E.A.F.; MIYADA, V.S.; PACKER, I.U. et. al. Uso de plasma suíno desidratado por Spray-dryer na dieta de leitões desmamados precocemente. Revista Brasileira de Zootecnia, v.28, n.3, p.326-333, 1999.

DANIELSON, A.D.; PEO Jr., E.R.; SHAHANI, K.M. Effect of feeding dried egg yolk on serum constituents in adult boars. Nutrition Reports International, v.40, p.227-231, 1989.

De RODAS, B.Z.; SOHN, K.S.; MAXWELL, C.V. et al. Plasma protein for pigs weaned at 19 to 24 days of age. Effect on performance and plasma insulin-like growth factor-I, growth hormone, insulin and glucose concentrations. Journal of Animal Science, v.76, p.3657-3665, 1995.

EGG PRODUCTS .http://www.aeb.org/proc/egg_products.html (10 fev. de 2000).

ERMER, P.M.; MILLER, P.S.; LEWIS, J.A. Diet preference and meal patterns of weanling pigs offered diets containing either spray-dried porcine plasma or dried skim milk. Journal of Animal Science, v.72, n.6, p.1548-1554, 1994.

FIALHO, E.T.; BELLAVER, C.; GOMES, P.C. et al. Composição química e valores de digestibilidade de alimentos para suínos em diferentes pesos. Revista da Sociedade Brasileira de Zootecnia, v.11, n.2, p.262-280, 1982a.

FIALHO, E. T.; FERREIRA, A. S.; GOMES, P., C. et al. Valores de composição química, balanço energético e protéico de alguns alimentos determinados com suínos de deferentes pesos. Revista da Sociedade Brasileira de Zootecnia, v.11, n.3, p.558-577, 1982b.

HANNAS, M.I.; KRONKA, R.N.; THOMÁZ, M.C. et al. Composição química, valores de energia e proteína digestíveis do plasma suíno e ovo desidratado por spray-dried para suínos. In: REUNIÃO ANUAL DA SOCIEDADE BRASILEIRA DE ZOOTECNIA, 38., 2001, Piracicaba. Anais... Piracicaba: Fundação de Estudos Agrários Luiz de Queiroz, 2001. p.851-852.

HANSEN, J.A.; NELSSEN, J.L.; GOODBAND, R.D. et al. Evaluation of animal protein supplements in diets of early-weaned pigs. Journal of Animal Science, v.71, n.7, p.1853-1862, 1993.

HARMON, B.G.; LATOUR, M.A.; DURST, J. Spray dried eggs as an ingredient in diets for SEW pigs. http:// www.ansc.purdue.edu/swine/swineday/sday00/psd032000.html (30 nov. 2000).

HARMON, B.G.; LATOUR, M.A.; NORBERG, S. The use of spray dried eggs as an ingredient in diets for infantile pigs and broilers. http://www.ansc.purdue.edu/swine/swineday/ sday01/sday01/10.pdf (13 jan. 2002). 
JAEN, J.F.; MAXWELL, C.V.; JOHNSON, Z.B. et al. Potential for egg protein as a protein source for phase 1 nursery diets. http://www.asas.org/jas/jointabs/iaafs48.pdf (15 fev. 2002).

MAKKINK, C.A.; BERNTSEN, P.J.; Op Den KAMP, B.M. et al. Gastric protein breakdown and pancreatic enzyme activities in response to two different dietary protein sources in newly weaned pigs. Journal of Animal Science, v.72, p.2843-2850, 1994.

MATTERSON, L.D.; POTTER, L.M.; STUTZ, M.W. et al. Research reports. Stors: The University of Connecticut Agricultural Experiment Station, 1965. 11p.

MENDONÇA Jr., C.X. Colesterol no Ovo - Possibilidades de sua Redução. In:. SIMPÓSIO LATINO - AMERICANO DE NUTRIÇÃO DE SUÍNOS E AVES, Campinas. Anais... Campinas: Colégio Brasileiro de Nutrição Animal, 1996. p.87-117.

MIYADA, V.S. A levedura seca na alimentação de suínos: estudos adicionais sobre o seu valor protéico e vitamínico. Piracicaba: Escola Superior de Agricultura "Luiz de Queiroz", 1987. 159p. Tese (Livre Docência) - Escola Superior de Agricultura "Luiz de Queiroz", 1989.

MOREIRA, I.; ROSTAGNO, H.S.; COELHO, D.T. et al. Determinação dos coeficientes de digestibilidade, valores energéticos e índices de controle de qualidade do milho e soja integral processados a calor. Revista da Sociedade Brasileira de Zootecnia, v.23, n.6, p.916-929, 1994.

NABER, E.C. Cholesterol content of eggs: can and should the industry try to change it? Feedstuffs, v.62, n.5, p.46-52, 1990.

NASCIMENTO FILHO, V.F.; ABDALA, A.L.; KORNDORFER, C.M. et al. Sensibilidades analíticas de diferentes modos de excitação em fluorescência de raios X para medida de trançadores em fezes de animais. In: ENCONTRO CIENTÍFICO DOS PÓS-GRADUANDOS DO CENA, Piracicaba. Resumos ... Piracicaba: CENA, 1997. p.69.

NESSMITH, W.B.; TOKACH, M.D.; GOODBAND, R.D. et al. Evaluation of various specialty protein sources as replacements for spray-dried animal plasma in diets for segregated early-weaned pigs. Kansas State University Swine Day Research Report, p.34-39, 1996.

NELSON, D.L.; COX, M.M. Amino acid oxidation and the production of urea. Lehninger principles of biochemistry. 3.ed. New York: Worth Publishers, 2000. p.623-658.
NORIN, S.L.; MILLER, P. S.; LEWIS, A. J. et al. Protein sources for segregated early weaned pigs. Journal of Animal Science, v. 76, suppl. 2, p.49, 1998.

OWEN, K.Q.; NELSSEN, J.L.; GOODBAND, R.D. et al. Effects of various fractions of spray-dried plasma on performance of early weaned pigs. Journal of Animal Science, v.73, p.81, 1995. (Suppl. 1)

PEINIAU, J.; AUMAITR, A.; LEBRETON, Y. Effects of dietary protein sources differing of nitrogen and pancreatic enzymes activity in early weaned pigs. Livestock Production Science, v.45, p.197-208, 1996.

PENZ Jr., A.M.; VIOLA, E.S. Nutrição. In: SOBESTIANSKI, J; WENTZ, I.; SILVEIRA, P.R.S. et al. (Eds.) Suinocultura intensiva: produção, manejo e saúde do rebanho. Brasília: Embrapa; Concórdia: Embrapa-CNPSA, 1998. p.47-63.

PUPA, J.M.R.; ROSTAGNO, H.S.; GOMES, P.C. et al. Determinação da digestibilidade dos nutrientes e da energia de alimentos utilizados em dietas para leitões. In: CONGRESSO BRASILEIRO DE VETERINÁRIOS ESPECIALISTAS EM SUÍNOS, 9., 1999, Belo Horizonte. Resumos... Belo Horizonte: MINASCENTRO, 1999. p.409-410.

ROSTAGNO, H.S.; ALBINO, L.F.T.; DONZELE, J.L. et al. Tabelas brasileiras para aves e suínos: composição de alimentos e exigências nutricionais. Viçosa, MG: Universidade Federal de Viçosa, 2000. 141p.

STATISTICAL ANALYSES SYSTEM - SAS. SAS user's guide: statistics. Version 6.11. Cary: 1996. 956p.

SERRANO, V.O.S. Digestibilidade dos aminoácidos de suplementos protéicos em suínos submetidos ou não a anastomose íleo-retal. Viçosa, MG: Universidade Federal de Viçosa, 1989. 55p. Dissertação (Mestrado) - Universidade Federal de Viçosa, 1989.

SILVA, D.J. Análise de alimentos (Métodos químicos e biológicos). 2.ed. Viçosa, MG: Universidade Federal de Viçosa, 1990. 165p. 